\title{
Measuring body temperatures in small lacertids: Infrared vs. contact thermometers
}

\author{
Miguel A. Carretero \\ CIBIO, Centro de Investigação em Biodiversidade e Recursos Genéticos, Universidade do Porto, Vairão, Portugal. \\ Correspondence: CIBIO, Centro de Investigação em Biodiversidade e Recursos Genéticos, Universidade do Porto, Campus \\ Agrário de Vairão, 4485-661 Vairão, Portugal. E-mail: carretero@cibio.up.pt
}

Received: 28 March 2012; received in revised form: 2 August 2012; accepted: 3 August 2012.

Infrared thermometers (IRT) are gaining popularity in herpetological thermal ecology due to their several advantages compared to contact thermometers (CT). To evaluate their accuracy in small lacertids, lab parallel measurements using IRT and CT are compared for a set of 52 adult lizards belonging to four different Podarcis forms, including males, pregnant and non-pregnant females, exposed to a photothermal gradient. Skin temperature was measured with an IRT and cloacal temperature with a CT at 10 time intervals, completing 520 paired measurements. Models of the relations were constructed using standardised major axis (SMA) regression. As expected, IRT and CT measurements were significantly correlated but determination coefficients were only moderate, IRT values being systematically higher. Moreover, the SMA regression lines deviated from slope 1 and intercept 0 in all cases, revealing a nonisometric bias; IRT tended to give progressively higher readings than CT for higher temperatures. Results provide methodological insights for further studies on thermal ecology of lacertids.

Key words: contact thermometers; infrared thermometers; Lacertidae; measurement bias; thermal ecology.

Medida de la temperatura corporal en pequeños lacértidos: Termómetros de infrarrojos vs. termómetros de contacto. El uso de termómetros de infrarrojos (IRT) se está popularizando en ecología térmica de anfibios y reptiles debido a una serie de ventajas respecto de los termómetros de contacto (CT). Con objeto de evaluar su exactitud en pequeños lacértidos, se comparan medidas paralelas tomadas en laboratorio con IRT y CT para un total de 52 lagartijas adultas pertenecientes a cuatro formas de Podarcis, incluyendo machos, hembras grávidas y hembras no grávidas, expuestas a un gradiente térmico. En 10 intervalos temporales, se midió la temperatura de la piel con un IRT y la cloacal con un CT, completándose un total de 520 registros dobles. Se construyeron modelos de regresión entre ambas variables mediante la regresión estandarizada del eje mayor (SMA). Aunque, como era de esperar, las medidas de IRT y CT se correlacionaron significativamente, los coeficientes de determinación fueron sólo moderados, siendo los valores de IRT sistemáticamente más elevados. Además, las rectas de regresión SMA se separaron de la pendiente 1 y del intercepto 0 en todos los casos, indicando un sesgo no isométrico, de modo que IRT tendió arrojar valores cada vez más altos que CT para temperaturas más elevadas. De estos resultados se derivan consecuencias metodológicas que deben tenerse en cuenta en futuros estudios de ecología térmica en lacértidos.

Key words: ecología térmica; Lacertidae; termómetros de contacto; termómetros de infrarrojos; sesgo de medida.

Being most functions in ectotherms temperature-dependent, accurate determination of body temperature is crucial to interpret their biological processes. Thus, numerous studies record body temperatures to analyse the proximate mechanisms linking temperature to physiology, life history, and behaviour of organisms (ANGILLETTA, 2010). Many of them use lizards as models and several have been conducted with lacertids (CASTILLA et 
al., 1999). However, obtaining reliable lizard temperatures may be problematic. The standard method consists of inserting a contact thermometer (CT), usually with a thermocouple probe but formerly with a fluid column, in the cloaca. However, this procedure forces the researcher to capture and handle the lizard, which may increase its metabolic rate, degree of stress (MOORE et al., 1991; LANGKINDE \& SHINE, 2006) and induce subsequent behavioural changes due to the disturbance, all potentially diminishing the representativeness of the temperatures recorded. Of the alternative methods proposed, implanted transmitters equally require lizard capture and surgery, and are usually more expensive and less suitable for small species (HARE et al., 2007). Because of that, infrared technology is gaining popularity, since reduced handling potentially provides more biological relevance to the measurements, minimises stress, prevents disease transmission and decreases reading time (HARE et al., 2007). More practical than the bulky and expensive infrared cameras, the portable infrared thermometers (IRT), essentially a pistol-shaped handle associated to a sensor and a laser pointer, are now widely used in lizard thermal ecology. Due to their low invasiveness, IRT offer advantages when working with small lizards. In fact, some of the early studies were carried out on lacertids (JONES \& AVERY, 1989; TOSINI et al., 1995), and these already stressed the necessity of a proper evaluation and calibration. Here is important to distinguish, following TAYLOR (1999), between precision (the degree to which repeated measurements show the same results) and accuracy (the degree of closeness of measurements). Even if IRT are highly precise, their accuracy cannot be simply assumed, but tested to prevent or correct systematic biases (ALFORD \& RAWLEY, 2007; HARE et al., 2007; ROWLEY \& AlFORD, 2007).

Here, parallel measurements using both types of thermometers are compared to determine the accuracy of IRT in small lacertids and the eventual pattern of bias if IRT readings are not accurate. It is assumed that CT provides a reliable measure of the lizard's core body temperature regardless it could result from lizard disturbance induced by the researcher.

\section{Materials AND MethodS}

A set of 52 adult lizards belonging to four different Iberian Podarcis forms were used as models for the experimental tests, namely, three representatives of the $P$. hispanica species complex (CARretero, 2008; Kaliontzopoulou et al., 2011, 2012), P. hispanica Galera type ( $\mathrm{N}=10$, Galera, Granada province, $37.744429^{\circ} \mathrm{N}$, $\left.2.549562^{\circ} \mathrm{W}\right)$, P. vaucheri Southern Spain $(\mathrm{N}=9$, Chiclana de la Frontera, Cadiz province, $\left.36.366937^{\circ} \mathrm{N}, 6.179339^{\circ} \mathrm{W}\right)$ and P. hispanica type $1 \mathrm{~B}(\mathrm{~N}=19$, Alba de Tormes, Salamanca province, $\left.40.825812^{\circ} \mathrm{N}, 5.515328^{\circ} \mathrm{W}\right)$, as well as $P$. muralis $(\mathrm{N}=14$, Tanes, Asturias province, $\left.43.205417^{\circ} \mathrm{N}, 5.400220^{\circ} \mathrm{W}\right)$.

Lizards of each locality were collected by noosing (GARCíA-MuÑoz \& Sillero, 2010) and brought to the laboratory. These samples, including males, pregnant and non-pregnant females, were considered as representative of the small lacertid lizards. Snout-vent lengths (SVL, mean $\pm \mathrm{SE}$ ), measured with a digital calliper to the nearest $0.01 \mathrm{~mm}$, were $45.21 \pm 0.71$ for $P$. hispanica Galera type, $58.53 \pm 0.85$ for P. vaucheri S Spain, $55.77 \pm 0.10$ for $P$. hispanica type $1 \mathrm{~B}$ and $55.98 \pm 0.91$ for $P$. muralis, respectively. 
Lizards were kept in individual terraria with food (Tenebrio molitor larvae and grasshoppers) and water provided ad libitum and under a natural regime of light and temperature. After an acclimatisation period of less than one week, they were individually exposed to a thermal gradient $\left(-20-50^{\circ} \mathrm{C}, 0.3 \times\right.$ $0.4 \times 1.0 \mathrm{~m}$ length experimental terrarium, see VerísSIMO \& CARRETERo, 2009) induced by a $100 \mathrm{~W}$ infrared reflector bulb fixed $15 \mathrm{~cm}$ above a sand substrate, maintaining the external natural photoperiod. The bulb was switched on with the lizards inside the terrarium one hour before the first measurement and voluntary temperatures were then recorded every hour at ten time intervals, between 9:00 and 18:00 (GMT). Skin temperature was first measured with an IRT (Fluke 68 , precision $0.1^{\circ} \mathrm{C}$, accuracy according to the manufacturer $\pm 1 \%$ ) directing the laser pointer to the centre of the lizard's back in line with the body axis (HARE et al., 2007), at a distance of approximately $20 \mathrm{~cm}$. According to the manufacturer specifications, this should restrict the area of infrared measurement to $2 \mathrm{~cm}$. After no more than 10 seconds since the IRT reading, the lizard was collected and the cloacal temperature was measured with a CT $\left(\mathrm{Hibok}^{\circ} 18\right.$, precision $0.1^{\circ} \mathrm{C}$, accuracy according to the manufacturer $\pm 0.2 \%$ ) associated to a k-thermocouple probe. Time between capture and CT reading did not exceed 10 seconds, which was sufficient for the reading to stabilise. After the experiments, lizards were again supplied with water and food ad libitum and then released in the capture sites.

Data were not transformed since distributions did not deviate from normality (Lilliefors tests, $P>0.05$ ), were homoscedas- tic (univariate Levene tests and multivariate Box $\mathrm{M}, P>0.05)$ and variances and means were uncorrelated. Tests were addressed to compare and relate the temperature measurements of IRT and CT, but not lizard populations or classes. However, since measurements were repeated for the same individual, analysis of variance (ANOVA) for repeated measures was performed to compare their means. Sphericity assumption was tested through Mauchley's tests. Pearson's correlations between both temperature readings were calculated. However, because both measurements carried an error, models of temperature relationships were constructed using standardised major axis regression (SMA) using the (S)MATR software (v.2 FALSTER et al., 2006). The remaining statistical tests were performed in Statistica 10 (STATSOFT, 2011).

\section{RESULTS}

In total, 520 paired measurements were recorded. Temperatures (Table 1) varied between 23.60 and $45.40^{\circ} \mathrm{C}$ for the IRT and between 24.00 and $37.90^{\circ} \mathrm{C}$ for the CT. Results of the ANOVA for repeated measures considering the 10 time intervals (Table 2) indicated thermometer type as the main factor of variation for temperature readings, which did not interact with the remaining factors. The IRT values tended to be systematically higher than the $\mathrm{CT}$ and this effect persisted for all Podarcis forms and time intervals (Fig. 1). This result remained even when only the temperatures recorded in the first interval were considered (Table 2).

Although the measurements of IRT and CT were significantly correlated, determination coefficients were only moderate. This was 
Table 1: Descriptive statistics of the temperature measurements by thermometer type and Podarcis form.

\begin{tabular}{|c|c|c|c|c|c|}
\hline \multirow[b]{2}{*}{ Podarcis forms } & \multirow[b]{2}{*}{$\mathrm{N}$} & \multicolumn{2}{|c|}{ Skin temperature IRT $\left({ }^{\circ} \mathrm{C}\right)$} & \multicolumn{2}{|c|}{ Cloacal temperature $\mathrm{CT}\left({ }^{\circ} \mathrm{C}\right)$} \\
\hline & & Mean \pm SE & Range & Mean \pm SE & Range \\
\hline P. hispanica Galera & 100 & $33.38 \pm 0.37$ & $24.80-40.50$ & $31.65 \pm 0.27$ & $24.00-35.60$ \\
\hline P. vaucheri S Iberia & 90 & $32.70 \pm 0.51$ & $23.60-31.88$ & $31.88 \pm 0.34$ & $25.60-37.90$ \\
\hline P. hispanica type $1 \mathrm{~B}$ & 190 & $33.67 \pm 0.28$ & $24.30-45.40$ & $31.87 \pm 0.19$ & $24.80-37.80$ \\
\hline P. muralis & 140 & $33.71 \pm 0.22$ & $25.70-40.10$ & $31.80 \pm 0.14$ & $27.40-36.70$ \\
\hline Pooled & 520 & $33.46 \pm 0.16$ & $23.60-45.40$ & $31.81 \pm 0.11$ & $24.00-37.90$ \\
\hline
\end{tabular}

Table 2: Results of the ANOVA for repeated measures on the temperature measurements considering the thermometer type (thermometer), the Podarcis form (form) and the time interval (time).

\begin{tabular}{lrrc}
\hline \hline ANOVA (10 time intervals) & F & d.f. & $P$ \\
\hline form & 0.71 & 3 & 0.56 \\
thermometer & 98.83 & 1 & $<10^{-6}$ \\
thermometer ${ }^{*}$ form & 1.16 & 3 & 0.35 \\
time & 1.41 & 9 & 0.18 \\
time ${ }^{*}$ form & 1.41 & 27 & 0.09 \\
thermometer ${ }^{*}$ time & 1.14 & 9 & 0.34 \\
thermometer ${ }^{*}$ time* form & 0.67 & 27 & 0.89 \\
\hline & & & \\
ANOVA (1st time interval) & F & d.f. & $P$ \\
\hline form & 1.44 & 3 & 0.25 \\
thermometer & 18.22 & 1 & $<10^{-5}$ \\
thermometer ${ }^{*}$ form & 1.40 & 3 & 0.26 \\
\hline
\end{tabular}

true both for the pooled data (Fig. 2), for the four Podarcis populations separately $\left(\mathrm{R}^{2}=0.487\right.$, $\mathrm{y}=1.473 \mathrm{x}-13.275$ in P. hispanica Galera type; $\mathrm{R}^{2}=0.442, \mathrm{y}=1.351 \mathrm{x}-9.384$ in $P$. vauche$r i \mathrm{~S}$ Spain; $\mathrm{R}^{2}=0.308, \mathrm{y}=1.589 \mathrm{x}-16.807$ in P. hispanica type $1 \mathrm{~B}$; and $\mathrm{R}^{2}=0.668, \mathrm{y}=1.502 \mathrm{x}$ - 15.187 in P. muralis) and for the different time intervals (not displayed). In all cases, the SMA regression lines deviated significantly from slope $=1$ and intercept $=0$ (Fig. 2, F = 162.59, $P<0.01$ and $\mathrm{T}=-9.149, P<0.01$, respectively, for the pooled data), while no slope dif- ferences were detected across populations or time intervals (test for common slopes $=48.401$, $P=0.448)$.

\section{DisCUSSION}

As expected, temperatures recorded with both types of thermometers were obviously related. However, such relation was not close, with IRT measurements deviating significantly from internal temperatures recorded with CT. Specifically, IRT values tended to be higher than $\mathrm{CT}$ ones, regardless other circumstances. More importantly, such bias was not constant (same slope, different intercept), but increased with the temperature (higher slope, different intercept). Remarkably, this bias cannot be attributed to the disturbance due to lizard manipulation, since it remained similar during the first temperature readings before lizards were ever captured inside the terrarium. In other words, regarding CT, IRT measurements were precise but not accurate (sensu TAYLOR, 1999).

What caused this bias? Biophysical models (STEVEnSON, 1985; FeI et al., 2012) allow the discard of substantial differences of temperature between the skin and core body in small lizards ( $<100 \mathrm{~g})$. Two recent studies comparing parallel IRT and CT measures reported dissimilar results for amphibian and lizards. While 

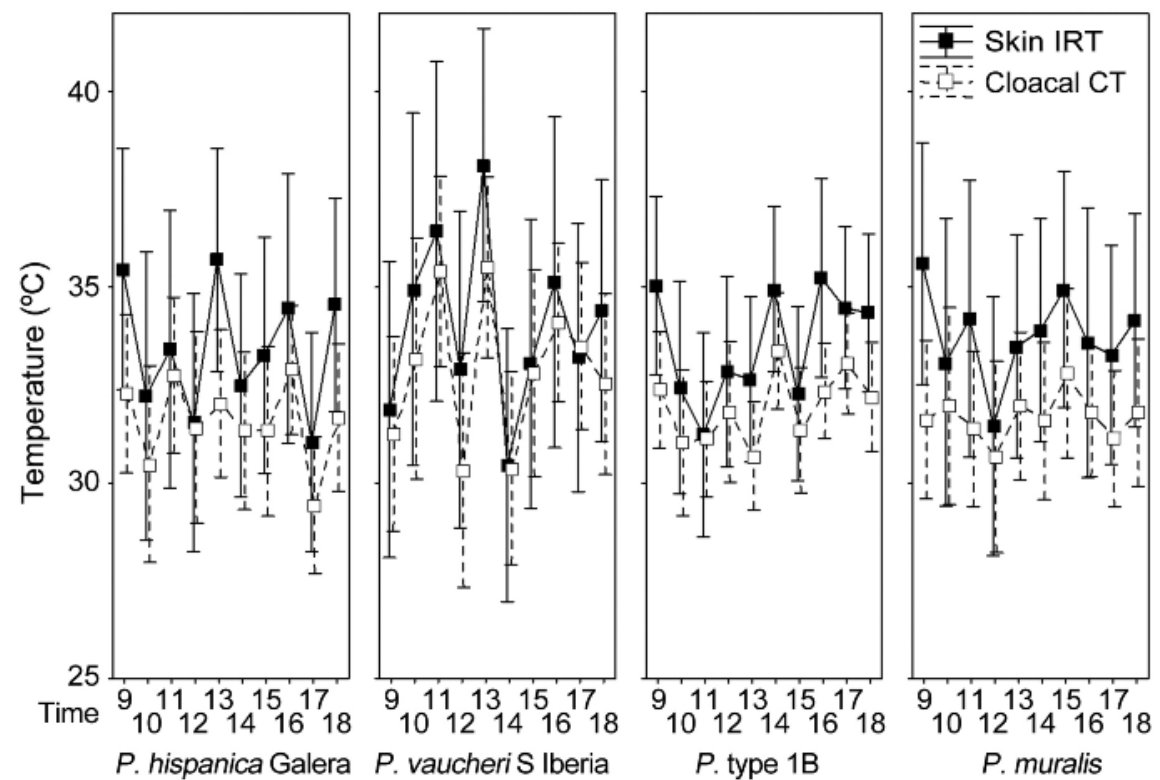

Figure 1: Variation of the temperature measurements using infrared (IRT) and contact (CT) thermometers according to the Podarcis form and time interval.

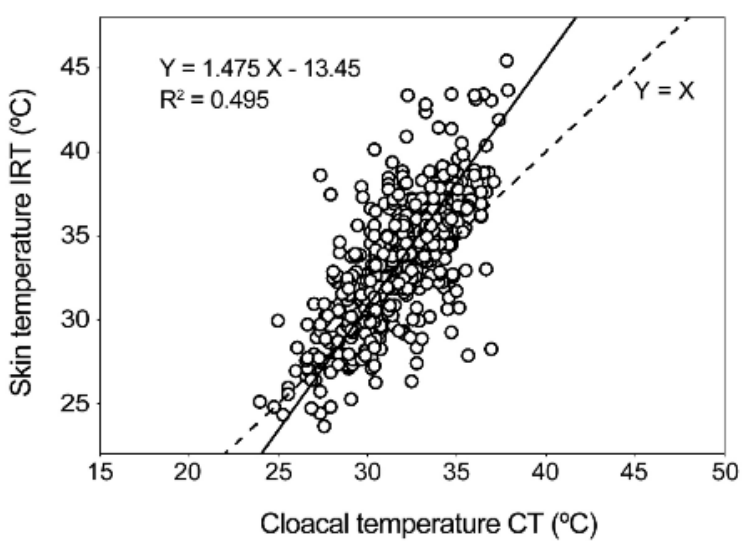

Figure 2: Comparison of the infrared (IRT) and contact (CT) temperature measurements pooled for the whole lizard sample.

correspondence was almost complete in bulkyshaped anurans (ROWLEY \& ALFORD, 2007), it was strongly dependent on body mass and orientation in slender lizards (HARE et al., 2007). This suggests that, regardless the cautions taken with thermometer orientation and distance, the small, elongated body of these lacertids provided an insufficient (and probably variable) skin area for the infrared sensor, which would have also measured the background (substrate) infrared radiation (HARE et al., 2007). Further experiments with a broader spectrum of lizard sizes and species should determine to what extent the recorded bias depends on body mass, shape and heat source not only in lacertids but also in other families. In principle, large, bulky and tigmothermic lizards would be expected to display lower biases (HARE et al., 2007), although phylogenetic influences (via physiology) cannot be discarded.

Accounting and correcting the bias between IRT and CT may reveal more difficult than simply applying the general equation extracted from the linear regression. On one hand, the relation between both readings was not strong, despite temperatures taken in terrarium minimised measurement error in terms of distance to 
the lizard, reading area and time. Usual conditions in field work are predicted to make nothing but increasing the bias. Certainly, the bias could be minimised if the IRT could be approached to a minimal distance of the skin, but this would imply the disturbance or even the lizard capture (VASCONCELOS et al., 2012), hence, their invasiveness approaching that of CT. On the other hand, even if no IRT-CT slope differences were detected between groups, variation in body temperatures across species, classes, seasons and time intervals has commonly been reported in both lab and field conditions (CASTILLA et al., 1999; CARRETERO et al., 2005, 2006; VerísSimo \& CARRETERO, 2009). Thus, according to the pattern observed, shifts are expected to be higher in the most thermophile groups, suggesting that IRT would accentuate eventual inter- and intraspecific differences.

In conclusion, despite their low invasiveness, infrared thermometers provide biased data regarding internal body temperatures records, compared to contact thermometers. This prevents their uncritical use, at least in small lacertids. Interspecific comparisons between species, sexes, size classes and time intervals with different body temperatures expected are to be evaluated with caution and mixing temperature data coming from IRT and CT is not recommended.

\section{Acknowledgement}

Supported by the projects PTDC/BIA$\mathrm{BEC} / 101256 / 2008$ and PTDC/BIABEC/101256/2008 funded by Fundação para a Ciência e a Tecnologia (FCT, Portugal). Collecting permits provided by Junta de Andalucía, Junta de Castilla-León and Principado de Asturias. Experiments following the guidelines of University of Porto (Portugal). Several colleagues of CIBIO and N. Sillero helped in the field work. Two anonymous reviewers contributed with their comment to the improvement of an earlier draft of the manuscript.

\section{REFERENCES}

Alford, R.A. \& Rowley, J.J.L. (2007). Comment on Papers by Hare et al. and Rowley and Alford. Herpetological Review 38: 316.

Angilletta, M.J. JR. (2010). Thermal adaptation. Oxford University Press, Oxford.

Castilla, A.M.; Van Damme, R. \& BAUWENS, D. (1999). Field body temperatures, mechanisms of thermoregulation and evolution of thermal characteristics in lacertid lizards. Natura Croatica 8: 253-274.

CARRETERO, M.A. (2008). An integrated assessment of the specific status in a group with complex systematics: the Iberomaghrebian lizard genus Podarcis (Squamata, Lacertidae). Integrative Zoology 4: 247-266.

Carretero, M.A.; Roig, J.M. \& Llorente, G.A. (2005). Variation in preferred body temperature in an oviparous population of Lacerta (Zootoca) vivipara. Herpetological Journal 15: 51-55.

Carretero, M.A.; Marcos, E. \& de Prado, P. (2006). Intraspecific variation of preferred temperatures in the NE form of Podarcis hispanica, In C. Corti; P. Lo Cascio \& M. Biaggini (eds.) Mainland and Insular Lacertid Lizards: a Mediterranean Perspective. Firenze University Press, Florence, pp. 55-64.

Falster, D.S., Warton, D.I. \& Wright, I.J. (2006). SMATR: standardised major axis tests and routines, Version 2.0. Available at: 
http://www.bio.mq.edu.au/ecology/SMAT R/. Retrieved on 02/24/2012.

Fei, T.; Skidmore, A.K.; Venus, B.; Wang, T.; Schlerf, M.; TOXOpeUs, B.; VAN Overjuj, S.; Bian, M. \& Lui, Y. (2012). A body temperature model for lizards as estimated from the thermal environment. Journal of Thermal Biology 37: 56-64.

García-Muñoz, E. \& Sillero, N. (2010).

Two new types of noose for capturing herps. Acta Herpetologica 5: 259-263.

Hare, J.R.; Whitworth, E. \& Cree, A. (2007). Correct orientation of a handheld infrared thermometer is important for accurate measurements of body temperatures in small lizards and Tuatara. Herpetological Review 38: 311-315.

JONES, S.M. \& AVERY, R.A. (1989). The use of a pyroelectric vidicon infra-red camera to monitor the body temperatures of small terrestrial vertebrates. Functional Ecology 3: 373-377.

Kaliontzopoulou, A.; Pinho, C.; Harris, D.J. \& Carretero, M.A. (2011). When cryptic diversity blurs the picture: a cautionary tale from Iberian and North African Podarcis wall lizards. Biological Journal of the Linnean Society 103: 779-800.

Kaliontzopoulou, A.; Carretero, M.A. \& Llorente, G.A. (2012). Morphology of the Podarcis wall lizards (Squamata: Lacertidae) from the Iberian Peninsula and North Africa: patterns of variation in a putative cryptic species complex. Zoological Journal of Linnean Society 164: 173-193.

LANGKInde, T. \& SHINE, R. (2006). How much stress do researchers inflict on their study animals? A case study using a scincid lizard, Eulamprus heatwolei. Journal of Experimental Biology 209: 1035-1043.
Moore, M.C.; Thompson, C.W. \& MARLER, C.A. (1991). Reciprocal changes in corticosterone and testosterone levels following acute and chronic handling stress in the Tree Lizard, Urosaurus ornatus. General and Comparative Endocrinology 81: 217-226.

Rowley, J.J.L. \& Alford, R.A. (2007). Non-contact infrared thermometers can accurately measure amphibian body temperatures. Herpetological Review 38: 308-311.

STEVEnson, R.D. (1985). Body size and limits to the daily range of body temperature in terrestrial ectotherms. American Naturalist 125: 102-117.

STATSOFT, INC. (2011). STATISTICA (data analysis software system), version 10 . Available at http://www.statsoft.com.

TAYLOR, J.R. (1999). An Introduction to Error Analysis: The Study of Uncertainties in Physical Measurements. University Science Books, Sausalito, California, USA.

Tosini, G., Jones, S. \& Avery, R.A. (1995). Infra-red irradiance and set point temperatures in behaviourally-thermoregulating lacertid lizards. Journal of Thermal Biology 20: 497-503.

VASCONCElos, R.; SAntos, X. \& Carretero, M.A. (2012). High temperatures constrain microhabitat selection and activity patterns by the insular Cape Verde wall gecko. Journal of Arid Environments 81: 18-25.

Veríssimo, C.V. \& Carretero, M.A. (2009). Preferred temperatures of Podarcis vaucheri from Morocco: intraspecific variation and interspecific comparisons. Amphibia-Reptilia 30: 17-23. 